Child Injury Division, Bureau of Reproductive and Child Health, Laboratory Centre for Disease Control, Health Protection Branch, Health Canada, Ottawa S G Mackenzie

Epidemiology and Biostatistics, McGill University and Injury Prevention Program, Montreal Children's Hospital, Montreal I B Pless

Correspondence to: Dr S G Mackenzie, LCDC Building, Tunney's Pasture 0601E2, Ottawa, Ontario K1A 0L2, Canada.

\title{
CHIRPP: Canada's principal injury surveillance program
}

\author{
Susan G Mackenzie, Ivan Barry Pless
}

Surveillance is often held to be a key element in the development of effective injury prevention programs. When based in emergency rooms, it provides better estimates of the magnitude of the injury problem than mortality data alone. Ideally, surveillance also provides early warnings of new hazards and may be used for program evaluation.

Before 1990, in Canada only statistics on mortality, hospitalizations, and from some surveys of specific injuries, were available. There was little information on the occurrence of injuries severe enough to require medical care but not necessitating a hospital admission. Without such data injuries arising from new causes could not be identified quickly and it was difficult to evaluate intervention programs using injuries as the outcome.

The Canadian Hospitals Injury Reporting and Prevention Program (CHIRPP) is an emergency room based injury surveillance system that operates in 10 pediatric and six general hospitals. Technical and financial support are provided by the Child Injury Division (CID) of the Laboratory Centre for Disease Control (LCDC), a Directorate of Health Canada (Canada's federal Department of Health). The main office of the program is in Ottawa; participating hospitals are located in seven provinces and one territory.

This paper provides an account of the development and operation of CHIRPP which was created in response to Canada's need for better data. This detailed description is intended to help colleagues in other countries who have similar concerns. Many papers have used data from this program, ${ }^{1-24}$ but no comprehensive description of it has been published previously.

\section{Origins of the program}

Following a visit to Australia in 1988, one of us (IBP) initiated efforts to create a system similar to its National Injury Surveillance and Prevention Program (NISPP) in Canada. The first step was to convince hospital administrators that such a system was important and feasible. Accordingly, directors of all the children's hospitals' emergency departments were invited to a conference. ${ }^{25}$ Subsequently, all agreed to support this initiative and each hospital then obtained the approval of its ethics committee for data to be sent to Ottawa. This was possible because parental consent was incorporated in the program.

The next step involved obtaining permission from the Ministry of Health of Australia to use, at no cost, the NISPP software, coding system, and data collection forms. To further facilitate Canadian government agreement, Hewlett Packard Canada was persuaded to donate computers to all 10 children's hospitals. In 1990, Health Canada officially launched CHIRPP as a three year feasibility program.

\section{Initial operation}

All children presenting to the emergency rooms at the 10 children's hospitals for an injury or poisoning were invited to participate. Accompanying adults (or the children, if old enough) completed a one page questionnaire about the circumstances of the injury. Physicians were asked to record clinical information on the back of the same form.

Initially, each hospital had a director and a clerk. The clerk coded the forms and entered the data onto the hospital's database. Copies were sent to Ottawa at monthly intervals for incorporation into the main database. The director's position, which is unpaid, was usually filled by the physician in charge of the emergency room. Responsibilities include obtaining the cooperation of emergency room staff in the distribution and completion of forms, and supervising the clerk.

\section{Subsequent developments}

Following a review in 1991 a number of changes were made. The most important involved moving data entry to Ottawa, engaging hospital based coordinators to replace the clerks, and upgrading the software. When data entry was hospital based there were an unacceptable number of coding errors and inconsistencies. Data entry was therefore centralized in Ottawa and four clerks were hired. Ongoing training and opportunities to discuss difficulties led to marked improvements in coding. After data are entered, the forms are shredded or returned. An updated database is sent to each hospital after every batch of records is entered, about once a month. Data are available for analysis within three and one half months of the event. 
Most of the coordinators have experience as unit clerks, medical records technicians, or nurses. Their responsibilities include achieving a high level of data capture, liaising with the central office, and basic data analyses. Some coordinators obtain missing information on circumstances through telephone calls or ward visits and missing clinical information from the charts. They work part or full time, depending on the size of the hospital and how much form completion they do. One year after they began there was a $32 \%$ increase in the number of cases captured.

COMMUNICATION

To facilitate communication between hospitals and the central office, a toll-free telephone line was installed in the CID. In addition, directors' and coordinators' meetings are held annually. Communication with the hospitals and with a broader national and international audience has been enhanced by publication of a newsletter and through the internet. CHIRPP News, an eight page newsletter with a circulation of 1500, has been published three times a year since 1994 (copies may be obtained by writing to the editor; see end of paper for details). It contains brief reports about selected types of injuries, ${ }^{26-36}$ and news of activities at participating hospitals and at the CID.

The injury section of LCDC's web site ${ }^{37}$ was inaugurated in 1996 and by July 1998 it was receiving more than 900 visits each week. The site includes general information about CHIRPP, injury reports based on CHIRPP data, and back issues of CHIRPP News. Summary tables of CHIRPP data, and of injury mortality and hospitalization data are also provided on the site.

SOFTWARE REVISION

In 1992 the NISPP software was rewritten to improve processing speed. Five years later the main database was transferred to a custom designed Oracle system that runs on an HP-755 RISC workstation. ${ }^{38}$ This conversion was necessary primarily because of the size of the database (630 000 records at the start of 1997).

At the time of conversion changes were also made to the coding, especially codes for factors involved in injuries. A hierarchical structure was developed and the number of factor codes reduced from 1186 to 728 . Addition of a second variable to code the place of occurrence permits more detailed specification of this aspect. Coding of body part was simplified and made hierarchical.
PROGRAM EXPANSION

Six general hospitals, which asked to join the program, were added between 1991 and 1994, thus providing some information on adult injuries and injuries in Northern and aboriginal communities. However, complete community coverage is only available at three sites.

STAFF AND FUNDING

Ongoing funding has been provided by Health Canada since the 1992-93 fiscal year and covers all program expenses at most hospitals. In the 1998-99 fiscal year hospitals will receive an average of $\$ 2.88$ for each form. At smaller hospitals, the cost per form is higher.

At present, LCDC staff working mostly on CHIRPP includes four data entry clerks, two research assistants, a communications officer, and a senior analyst. In addition, the chief of the CID, a clerk, a systems analyst, and a senior epidemiologist spend less than $50 \%$ of their time on CHIRPP. Other costs include office overhead, postage and courier services, printing, hardware and software maintenance, site visits, and travel.

\section{CHANGE OF NAME}

CHIRPP's original name was the Children's Hospitals Injury Research and Prevention Program. The present name was adopted in 1992 after general hospitals joined the program.

\section{Information in the database}

Information about the injured person includes date of birth, sex, home language, and postal code. Translation of narratives that describe circumstances in which injuries occur into coded variables requires a sophisticated coding system.

The principal variables that describe circumstances and some of the values they can take are shown in table 1. Although the use of most variables is apparent, the three different kinds of factors are more complicated. More than 700 values are available for coding breakdown, mechanism, and contributing factors and two of each type of factor may be entered for a single event. A selected factor code value might be used for any of these factors. For example:

- A breakdown factor is an item whose failure or malfunction led to the injury, such as a swing whose chain broke.

- A mechanism factor is one that directly caused the injury, such as a swing, if it was in motion and hit a child running by.

- A contributing factor is one involved in the injury that did not malfunction and was not the

Table 1 Principal CHIRPP variables used to describe circumstances

\begin{tabular}{|c|c|c|}
\hline Variable & No of values & Examples \\
\hline Location & 57 & Own home, school, public park, highway \\
\hline Area & 48 & Bathroom, stairs, swimming pool, bicycle path/lane \\
\hline Context & 47 & Pedestrian, informal sports, food preparation, eating \\
\hline Breakdown event & 22 & $\begin{array}{l}\text { Fall on same level, collision, spill, structural fire, failure, } \\
\text { malfunction }\end{array}$ \\
\hline Breakdown, mechanism or contributing factors & 728 & $\begin{array}{l}\text { Window glass, dog, television, barbeque, hammer, } \\
\text { acetaminophen, dishwasher detergent, coffee table, ice } \\
\text { hockey, light bulb, iron, radiator, lawn mower, swing }\end{array}$ \\
\hline Intent & 7 & $\begin{array}{l}\text { Unintentional, intentional self harm, maltreatment by } \\
\text { parent or caregiver, sexual assault }\end{array}$ \\
\hline
\end{tabular}


direct cause, such as a swing, if a child fell from it. Contributing factors also include any specific sport or the involvement of drugs or alcohol.

Other information about circumstances includes the date and time, safety devices, vehicle seating position, and, if injury was work related, the industry and occupation.

Based on what was known in the emergency room, up to three injuries can be described on the data form. Injury and body part codes are paired (for example superficial injury and face, fracture and forearm, etc). A single variable describes disposition (for example advice only, follow up, or admitted) and is often used as an indicator of severity.

Three free text variables describe how the injury happened, where for example, name of playground or address, and details about products such as brand name or model number. Text searches facilitate the retrieval of records that involve items or circumstances for which no specific code exists, for example, a particular type of machinery or the name of a medication.

\section{QUALITY ASSURANCE}

Quality control, particularly with respect to capture and accuracy of coding, is continuous. As of 1996, at the 14 hospitals for which estimates were available, the median capture was $88 \%$ (range $24 \%-100 \%$ ). Coding accuracy is much improved since 1992. The data entry program performs logic checks and warns when unlikely combinations are entered. Before undertaking detailed analysis, information from the text is often used to correct errors.

DATA ANALYSIS ISSUES

Because older patients are under-represented, it is misleading to attempt to compare the raw numbers or percentages of CHIRPP injury reports among, for example, 10-14 year olds and 15-19 year olds or adults. It is more appropriate to report age specific proportions of all injuries accounted for by a particular type of injury. For example, table 2 shows that there are 1.6 times as many injuries associated with snowboarding among 10-14 year olds as among 15-19 year olds. However, when the proportions of snowboarding injuries among injuries of all kinds are examined, the situation is reversed: the proportion is 1.4 times higher among $15-19$ year olds than among $10-14$ year olds.

Similarly, although CHIRPP data cannot be used to estimate temporal trends, it is possible to examine these trends in the proportions of certain types of injuries. For example, the pro-

Table 2 Results of different approaches to comparing the frequency of snowboarding injuries among patients of different ages

\begin{tabular}{lrc}
\hline $\begin{array}{l}\text { Age } \\
\text { (years) }\end{array}$ & $\begin{array}{l}\text { No (\%) of } \\
\text { injuries }\end{array}$ & $\begin{array}{l}\text { Rate/100 000 all } \\
\text { injuries }\end{array}$ \\
\hline $1-4$ & $3(0.3)$ & 5 \\
$5-9$ & $39(4.2)$ & 82 \\
$10-14$ & $501(54.5)$ & 883 \\
$15-19$ & $309(33.6)$ & 1275 \\
$20+$ & $68(7.4)$ & 151 \\
\hline
\end{tabular}

portion of injuries associated with in-line skating among all injuries rose from 44/100 000 to 881/100 000 between 1991 and 1996 .

The coding system permits capture of a wide range of information about the circumstances in which injuries occur. This complexity means, however, that inexperience in working with these data can lead to problems. Failure to retrieve all relevant cases may result from a lack of understanding of the coding system or from failure to search text fields. Because coding errors are inevitable, especially in the older data, we use several approaches when searching for a particular injury. For example, to be certain of finding all cases of burns or scalds we search for cases in which the nature of injury was burn or corrosion or the mechanism was contact with hot objects, open fire, flames, coals, hot liquids, or steam. Unless the size of the data set precludes it, each record is reviewed to be certain that the coding of key variables agrees with information in the text fields.

In data analysis the use of new variables created to classify specific information from text fields, particularly the injury event description, can be very useful. For example, in a study of injuries associated with air guns, the text often provided information about who was handling the weapon when it discharged. Similarly, in a study of injuries associated with bunk beds, a new variable described which level bunk the child was using.

In addition, the use of at least two dimensional tables gives much more useful information than can be obtained from one dimensional tables. Analyses are usually stratified by age group and the groups used can vary with the type of injury. Two dimensional tables are also useful in describing the injuries suffered. For example, when studying in-line skating injuries it is more informative to combine the nature of injury and body part and thus learn that $38 \%$ of the injuries are fractures of the upper extremity than it is to learn only that $42 \%$ of all injuries are fractures and $62 \%$ of all injuries affect the upper extremity. Adding age reveals that fractures of the upper extremity account for $43 \%$ of injuries among patients under 15 years, but only $23 \%$ of those aged 15 years and older.

\section{Applications}

In the CID, about $65 \%$ of the time of a data analyst is spent responding to requests for information. About six such requests were received each week in 1997, mostly from hospitals and non-governmental organizations (22\% each), other parts of the federal government (13\%), local government (most often health units), and the media ( $9 \%$ each). Forty four per cent involved sending a copy of a previously prepared report; only $21 \%$ required a new analysis. Approximately two thirds were handled in less than an hour. When it is felt that the information would be of general interest, a CHIRPP Injury Report is prepared and posted on the web. ${ }^{37}$ Titles of these reports are listed in CHIRPP News periodically (Appendix). Brief articles based on the data are published in 
CHIRPP News; detailed work is published in scientific journals or presented at conferences. A recently published book on child injury in Canada made substantial use of information from CHIRPP. ${ }^{39}$ Each chapter dealing with a specific type of injury relied heavily on information from the program to describe the circumstances in which these injuries occur.

When a project requiring use of program data is led by researchers outside the division, the work often becomes a collaborative effort, with analysis done by CID staff. This has two advantages: maintenance of confidentiality and having the analysis done by someone who understands the information well. Raw data are released to outside researchers only when a protocol is approved, all identifiers are removed, and the researcher agrees not to distribute the material to others and to destroy it upon completion.

Individual hospitals use their information as they see fit. Some provide raw data for use by local public health units or use results to respond to local requests, to prepare regular summaries for local circulation, and sometimes for meetings or publications. The principal reasons for not using results more extensively are lack of training, time, or funds. In an attempt to overcome some of these problems a local research support program was initiated in 1997. Modest funding is now available to support simple, hospital based analyses or projects.

\section{Discussion}

When CHIRPP was implemented it was expected it would serve to (1) assist in the identification of emerging hazards, (2) provide information that would be useful in developing injury prevention and control programs and policies, and (3) provide a tool to evaluate these programs. Now, after nearly 10 years in operation, it is evident it has been reasonably successful in each of these goals.

It provides rich information on the circumstances in which injuries occur. The types of injuries studied range from those that are common to others that are rare. The latter are often brought to attention by the media, the public, or by data entry clerks. We have not yet found a way to scan the database to signal previously unrecognized types of injuries. However, once we are aware of a hazard, it is easy to track it.

CHIRPP is less often used to develop or evaluate prevention programs. Although data on circumstances are well suited to intervention planners, it is usually difficult to know what use is made of the information that is provided. There are, however, some encouraging exceptions: the Canadian Standards Association, in revising standards for play spaces and equipment, ${ }^{40}$ used CHIRPP. Additionally, seven Canadian Tire stores in Winnipeg offered a $\$ 5$ coupon for each baby walker brought in to be destroyed, ${ }^{41}$ CHIRPP data on walker related injuries that occurred before and after the program are being used to evaluate it.
STRENGTHS AND LIMITATIONS

The principal strength of CHIRPP is the information on how injuries happen-information that provides insights useful for prevention. Information reported directly by patients is particularly valuable, as they know most about how the injury occurred. In contrast, self reports are less valuable if the reporter is illiterate or reluctant to provide information. In two communities where illiteracy is a problem, emergency room staff record as much detail as possible in the chart for use by coordinators. Reluctance to complete forms is most likely when the injury involves violence. In these cases information is obtained from the medical record.

A major limitation is representativeness. Only three communities, in which all hospitals with emergency rooms participate, can provide population based rates. The 16 participating hospitals are a small sample of the more than 750 Canadian hospitals that provide emergency room treatment of injuries. Because they are not representative, it is inappropriate to use the data to estimate the numbers of injuries in Canada, or even the number treated in Canadian emergency rooms.

A study in Montreal revealed that $38 \%$ of children treated for an injury by a physician were cared for in either of the two CHIRPP hospitals in that city (unpublished data). Thus, it is generally inappropriate to use the data to compare the occurrence of injuries in different communities using CHIRPP data.

Even in communities that have complete coverage of emergency room visits, some injuries are not captured. This includes those for which treatment is not sought and those treated elsewhere. Initially, there was also under-representation of seriously injured patients because they bypass the usual registration procedures. Recently, however, coordinators have been obtaining information about these patients.

Injuries of patients who refuse to complete the forms may also be missed but most ethics committees have approved the collection of the relevant information from charts. Such forms, completed by coordinators, note that consent for follow up was refused.

Fatal injuries are under-represented because some victims who die immediately after being injured are never brought to hospital and because no follow up is done to identify deaths that occur after patients leave the emergency room. Further, because data are based on what is known in the emergency room, the database contains no information on the duration of hospitalization or on sequelae.

Under-representation of older adolescents and adults arises because of the high proportion of children's hospitals in the program. Even before teenagers become too old to be treated at pediatric hospitals, they are increasingly likely to seek care at general hospitals.

\section{Implications for prevention}

It is clear that much remains to be done to increase the extent to which surveillance data 
are used to reduce the burden of injury. What is not clear is how this process can be catalysed or even which bodies are responsible for doing so. Unlike the US, for example, where the National Center for Injury Prevention and Control funds some intervention programs, ${ }^{42}$ no such funding source exists in Canada. At the provincial and territorial level, public health departments could establish prevention programs based on CHIRPP using their base budgets.

Questions have been raised about the value of continuing to add more records to an already large database. If data collection does not continue, however, it will not be possible to provide information on new causes. Nor will it be possible to study trends in the proportions of emerging injury types, or of any changes in the circumstances of injuries associated with particular factors. Termination would also preclude evaluation of current and future interventions.

A number of gaps that CHIRPP cannot fill could be met by complementary programs, such as wider use of a minimum data set or a national coroners' database. Both would contribute to a more complete picture of the occurrence of injury in Canada.

\section{Appendix}

Available CHIRPP Reports: topics and age group, 1994-98

\begin{tabular}{|c|c|c|}
\hline Type of injury & Age group & Year of report \\
\hline \multicolumn{3}{|l|}{ Products (all ages) } \\
\hline Bathtubs & $<16$ years & 1994 \\
\hline Bunkbeds & $<19$ years & 1998 \\
\hline Dishwashers & All & 1994 \\
\hline Drinking glasses & $<8$ years & 1994 \\
\hline Garage doors & All & 1995 \\
\hline Kettles & All & 1998 \\
\hline Washers and dryers & $<10$ years & 1998 \\
\hline \multicolumn{3}{|l|}{ Products (infants and toddlers) } \\
\hline Baby gates & $<5$ years & 1997 \\
\hline Baby walkers & $<5$ years & 1997 \\
\hline Cribs and cradles & $<5$ years & 1997 \\
\hline Infant swings & $<18$ months & 1995 \\
\hline Strollers and carriages & $<6$ years & 1997 \\
\hline \multicolumn{3}{|l|}{ Sports and recreation } \\
\hline Drowning and near drowning & $<6$ years & 1994 \\
\hline Downhill skiing & All & 1998 \\
\hline Equestrian activities & All & 1995 \\
\hline In-line skating & All & 1995 \\
\hline In-line skating & All & 1998 \\
\hline Goal posts & $<20$ years & 1994 \\
\hline Playground equipment & $<20$ years & 1998 \\
\hline Ringette & All & 1994 \\
\hline Rugby & All & 1995 \\
\hline Skateboards & All & 1998 \\
\hline Soccer & $<20$ years & 1998 \\
\hline Snowboarding & All & 1998 \\
\hline Trampolines & All & 1994 \\
\hline \multicolumn{3}{|l|}{ Toys } \\
\hline Ride-on toys & $<10$ years & 1994 \\
\hline Toys aspirated or swallowed & $<10$ years & 1994 \\
\hline Toys & All & 1998 \\
\hline Tricycles & $<10$ years & 1994 \\
\hline \multicolumn{3}{|l|}{ Transport } \\
\hline Bicycles & All & 1994 \\
\hline Pedestrian and bicyclist victims of motor vehicle crashes & All & 1994 \\
\hline Personal powered watercraft & All & 1995 \\
\hline School buses & $<20$ years & 1995 \\
\hline \multicolumn{3}{|l|}{ Other } \\
\hline Dogbites & All & 1994 \\
\hline Electrical injuries & $<19$ years & 1994 \\
\hline Farm injuries & $<20$ years & 1994 \\
\hline Pesticides & $<20$ years & 1994 \\
\hline Shopping carts & $<5$ years & 1995 \\
\hline Tap water scalds & All & 1994 \\
\hline
\end{tabular}

\section{Conclusion}

CHIRPP has developed well in the nine years since it began. More than 110000 records are now added each year; computer software designed to meet specific needs is available for data entry and maintenance; and there is good support for both software and hardware. The database of almost 900000 records provides a wealth of information about how injuries happen. The challenge that remains is to find ways to use this system to more effectively prevent injuries. The cooperation of the following hospitals is deeply appreciated:
Dr Charles A Janeway Child Health Centre, St John's, Newfoundland; I W K Grace Health Centre, Halifax, Nova Scotia; Centre hositalier régional de Rimouski, Rimouski, QueScotia; Centre hositalier régional de Rimouski, Rimouski, Que-
bec; Hôpital Enfant-Jésus, Quebec, Quebec; Hôpital Ste-Justine bec; Hôpital Enfant-Jésus, Quebec, Quebec; Hôpital Ste-Justine
and Montreal Children's Hospital, Montreal, Quebec; Chiland Montreal Children's Hospital, Montreal, Quebec; Children's Hospital of Eastern Ontario, Ottawa, Ontario; Hotel
Dieu Hospital and Kingston General Hospital, Kingston, Dieu Hospital and Kingston General Hospital, Kingston,
Ontario; Hospital for Sick Children, Toronto, Ontario; Children's Hospital of Western Ontario, London, Ontario; Sioux Lookout Zone Hospital and associated nursing stations, Sioux Lookout, Ontario; Winnipeg Children's Hospital, Winnipeg, Manitoba; Alberta Children's Hospital, Calgary, Alberta; British Columbia's Children's Hospital, Vancouver, British Columbia; Stanton Regional Hospital and associated nursing stations, Yellowknife, Northwest Territories.

We acknowledge the source of this article as Health Canada. Reproduced with the permission of the Minister of Public Works and Government Services Canada, 1999.

CHIRPP News is available at no charge. To subscribe, write to the Editor, CHIRPP News, Child Injury Division, Bureau of
Reproductive and Child Health, Health Canada, LCDC BuildReproductive and Child Health, Health Canada, LCDC Build-
ing, Tunney's Pasture (0601E2), Ottawa, Ontario, K1A 0L2, ing, Tun

1 Ellison L. Basketball injuries in the database of the Canadian Hospitals Injury Reporting and Prevention Proram (CHIRPP). Chronic Diseases in Canada 1995;16:11724 .

2 Ellison LF, Mackenzie SG. Sports injuries in the database of the Canadian Hospitals Injury Reporting and Prevention Program - an overview. Chronic Diseases in Canada 1993; 14:96-104.

3 Mackenzie SG, Sherman GJ. Day-care injuries in the database of the Canadian Hospitals Injury Reporting and Prevention Program. Pediatrics 1994;94(6 suppl):1041-3.

4 Mackenzie SG. Work-related injuries among people aged less than 20 years in the database of the Canadian Hospitals Injury Reporting and Prevention Program (CHIRPP). Canadian fournal of Pediatrics 1993;5:301-7.

5 Mackenzie SG. Injuries associated with hooks in retail displays. Chronic Diseases in Canada 1992;13:116-7.

6 Sherman GJ. Trampoline-related injuries in the Children's Sherman GJ. Trampoline-related injuries in the Children's Diseases in Canada 1990;11:88-90.

7 Sherman GJ. Gathering and analyzing data on injuries. Chronic Diseases in Canada 1990;11:60-1.

8 Sherman GJ. Trampoline-related injuries in the Children's Hospital Injury, Research and Prevention Program: an update. Chronic Diseases in Canada 1991;12:78-80.

9 Bienefeld M, Pickett W, Carr PA. A descriptive study of childhood injuries in Kingston, Ontario, using data from a computerized injury surveillance system. Chronic Diseases in Canada 1996;17:21-7.

10 Flores J, Maurice P, Goulet C. Les consultations à l'Hopital de L'Enfant-Jésus de Québec (suite)-basket-ball, volleyball et football. Le Sécuritaire (Le bulletin d'information de la Régie de la sécurité dans les sports du Québec) 1996;15(2):3.

11 Laflamme P, Maurice P, Laliberté D. Blessures liées à la pratique du hockey: consultations dans un centre hospitalier de la région de Québec. Can f Public Health 1996;87: 240-3.

12 Macarthur C, Dougherty G, Pless IB. Reliability and validity of proxy respondent information about childhood injury: an assessment of a Canadian surveillance system. Am f Epidemiol 1997;145:834-41.

13 Morrison, CD, Stanwick RS, Tenenbein M. Infant walker injuries persist in Canada after sales have ceased. Pediatr Emerg Care 1996;12:180-2.

14 Pickett W, Hartling L, Brison RJ. A population-based study of hospitalized injuries in Kingston, Ontario, identified via the Canadian Hospitals Injury Reporting and Prevention Program. Chronic Diseases in Canada 1997;18:61-9.

15 Pickett W, Carr PA, Mowat DL, et al. Playground equipment hazards and associated injuries in Kingston and area. Can 7 Public Health 1996;87:237-9.

16 Schwartz HJ, Brison RJ. Bicycle-related injuries in children: a study in two Ontario emergency departments, 1994. Chronic Diseases in Canada 1996;17:56-62.

17 Mowat DL, Wang F, Pickett W, et al. A case-control study of risk factors for playground injuries among children in Kingston and area. Inj Prev 1998;4:39-43. 
18 Morrison A, Stone DH. Injury surveillance in accident and emergency departments: to sample or not to sample? Inj

19 Linn S, Smith D, Sheps S. Epidemiology of bicycle injury, head injury, and helmet use among children in British Columbia: a five year descriptive study. Inj Prev 1998;4: $122-5$

20 Marshall DH, Brownstein S, Addison DJ, et al. Air guns: the main cause of enucleation secondary to trauma in children and young adults in the greater Ottawa area in 1974-93. Can F Ophthalmol 1995;30:187-92.

21 Ellis JA, Kierulf C, Klassen TP. Injuries associated with in-line skating from the Canadian Hospitals Injury Reporting and Prevention Program database. Can f Public Health 1995;86:133-6.

22 Finvers, KA, Strother RT, Mohtadi N. The effect of bicycling helmets in preventing significant bicycle-related injuries in Canada. Clin $\mathcal{F}$ Sport Med 1996;6:102-7.

23 Gibson H, Klassen T. How safe are our schools? Can f Public Health 1996;87:106-8.

24 Stone DH, Doraiswamy NV. The Canadian Hospitals Injury Reporting and Prevention Program (CHIRPP) in the UK: a pilot study. Inj Prev 1996;2:47-51.

25 Pless IB. National childhood injury prevention conference. Can $\mathcal{F}$ Public Health 1989;80:427-30.

26 Herbert $M$. In-line skating: rising popularity, more injuries. CHIRPP News 1994;(2):1,4-5.

27 Herbert M. Focus on children, kitchen and burns. CHIRPP News $1994 ;(3): 1,7$

28 Joubert G. Baby walkers in Canada: a survey of CHIRPP records. CHIRPP News 1994;(3):3.
29 Mackenzie SG. What can CHIRPP data tell us about child poisonings? CHIRPP News 1995;(5):3-5.

30 Herbert M. Snowmobiles: a profile of injuries. CHIRPP News 1995;(6):3.

31 Herbert M. Bicycle helmet use and serious head injury among injured bicyclists. CHIRPP News 1995;(6):4.

32 Mackenzie SG. Air-gun injuries in the CHIRPP database. CHIRPP News 1995;(6):5.

33 Brown J. A profile of sledding injuries. CHIRPP News 1996; (9):6.

34 Flores J, Maurice P. Feasibility study looks at CHIRPP data on bicycling-related injuries. CHIRPP News 1996;(9):7.

35 Flores J, Brown J, Mackenzie SG, et al. Innovative CHIRPP program focuses on dog-bites. CHIRPP News 1997;(11): 3-7.

36 Brown J. A comparison of injuries on various types of playground equipment. CHIRPP News 1997;(12):7.

37 URL: http://www.hc-sc.gc.ca/hpb/lcdc/brch/injury.html.

38 Mackenzie SG. CHIRPP database undergoes technical changes. CHIRPP News 1997;(10):3-5.

39 Health Canada. For the safety of Canadian children and youth: from injury data to preventive measures. (Catalogue number from injury data to preventive measures. (Catalogue

40 Canadian Standards Association. Children's play spaces and Canadian Standards Association. Children's play spaces and
equipment. (Catalogue number CAN/CSA-Z614-98.) Toronto: Canadian Standards Association, 1998.

41 Baby walkers destroyed. CHIRPP News 1997;(12):4

42 Sleet D, Bonzo S, Branche C. An overview of the National Center for Injury Prevention and Control at the Centers for Disease Control and Prevention. Inj Prev 1998;4:308-12.

\section{Deaths put a western tradition on trial}

In spite of two deaths and seven recent injuries to riders in the back of pick-up trucks in Alberta, there continues to be strong opposition to a proposed ban on this dangerous practice. In fact, three provinces still permit passengers to ride in the back of pick-ups. In the past, farmers were opposed because this was the method of choice for transporting large crews from one farm to another, but this is no longer the case. Nevertheless, for reasons best understood by its opponents, and in spite of the most recent tragedy - a teen who was thrown from the box of a pick-up when the vehicle went out of control-opposition continues. The Alberta minister responsible sagely observed: "My own personal opinion is that for work purposes, I think there's merit in not having any specific legislation". Can anyone understand this? Consistent with this enlightened view is the fact that Alberta was one of the last provinces to enact seat belt legislation. In spite of this, it is one of the few provinces to have a reasonably well funded injury prevention and control program. Go figure! (R Remington, National Post, June 1999).

\section{Practising safe violence}

If you must be violent, let it out on your computer. A recent survey in Britain, Rage Against the Machine, reveals that $80 \%$ of people reported seeing a colleague vent anger on a computer, often to the extent of actually damaging it. More specifically, one in four under 25 admitted physically assaulting their computer, and one in six stated that they "felt like taking their frustrations out on colleagues or office furniture". Others simply pull the plug on the monster. The term coined for this form of violence is "technology related anxiety". The report concludes, "The short-comings of computers led many workers to question whether computers were more of a burden than an asset" (Daily Telegraph (London)).

Editor's note: There are many days when I know precisely how they feel and wish I could get back at the monster!

\section{Helmets for some}

In spite of the BMA Board on Science and Technology's opposition to bike helmet legislation in Britain, some have decided that helmet use is beneficial. After a mechanic who was run over and seriously injured during the Indy 500 motor car race, the management of the Energizer Motorsports team have decided that their crews will all wear helmets at future Racing League events. Although there is no rule requiring pit crews to wear helmets, six teams are already wearing a prototype helmet designed by Bell Auto Racing. Officials hope to speed the development of these helmets. "Hindsight being 20-20, we are going to outfit all the crew with helmets, even the tire changers". 